\title{
Elogio de la apropiación. Prácticas impuras, flamenco y creación contemporánea
}

\author{
In Praise of Appropriation. Impure Practices, \\ Flamenco and Contemporary Creation
}

De la denominada "música saturada" al trap experimental, del flamenco contemporáneo al arte sonoro, la electrónica o la música académica actual, podríamos afirmar que una parte considerablemente significativa de la realidad musical española, hoy en día, sería susceptible de ser considerada como resultado de un proceso de apropiación, una suerte de palimpsesto en continua reconstitución y resignificación.

Teniendo en cuenta conceptos tan heterogéneos entre sí como pureza, distinción o cuerpo, y desde una adaptación -crítica y actualizada- del análisis tripartito de Jean-Jacques Nattiez, nos centraremos en el análisis del rastro intertextual presente en varios ejemplos emblemáticos del flamenco actual y la creación académica contemporánea, como los que personifican Niño de Elche o Rocío Márquez y Mauricio Sotelo o José María Sánchez-Verdú.

Palabras clave: apropiación, música impura, música actual, músicas urbanas, flamenco contemporáneo, Niño de Elche, Rocío Márquez, José María Sánchez-Verdú, Mauricio Sotelo, Federico García Lorca.

From so-called "saturated music" to experimental trap, from contemporary flamenco to sound art, electronics and contemporary art music, it would be true to say that a considerably significant proportion of the present Spanish musical reality could be considered a result of a process of appropriation, a kind of palimpsest in continuous reconstitution and re-signification.

This article considers concepts as heterogeneous as purity, and is based on a (critical and updated) adaptation of Jean-Jacques Nattiez's three-part analysis. It focuses on the analysis of the intertextual trail present in several emblematic examples of contemporary flamenco and art music, such as those personified by Niño de Elche; Rocío Márquez and Mauricio Sotelo; and José María Sánchez-Verdú.

Keywords: appropriation, impure music, contemporary music, urban musics, contemporary flamenco, Niño de Elche, Rocío Márquez, José María Sánchez-Verdú, Mauricio Sotelo, Federico García Lorca. 
Solo me interesa lo que no es mío.[...] Contra todos los importadores de conciencia enlatada. La existencia palpable de la vida. [...] Contra el mundo reversible y las ideas objetivadas. Cadaverizadas. El stop del pensamiento que es dinámico. El individuo víctima del sistema. Fuente de las injusticias clásicas. De las injusticias románticas.Y el olvido de las conquistas interiores. Rutas. Rutas. Rutas. Rutas. Rutas ${ }^{1}$.

A finales del año 2000, y bajo el signo del cambio de siglo, el Museo $\mathrm{Na}-$ cional Centro de Arte Reina Sofia de Madrid inauguraba una exposición titulada F[r]icciones. Versiones del sur. Como pilares conceptuales de una nutrida y muy heterogénea muestra, el catálogo ofrecía la conocidísima noción de ficción, descrita por el poeta y novelista Jorge Luis Borges, y, entre otros, el Manifiesto antropófago, al que pertenece la cita de apertura de nuestro texto. Casi dos décadas después, la práctica musical actual, especialmente si nos circunscribimos a nuestro objeto de estudio, consigue reacciones que también tienen que ver con una cierta noción de f[r]icción. Por citar solo algunos ejemplos, destaca la confusión de la periodista Niloufar Haidari, en el verano de 2017, al definir a la cantante catalana Bad Gyal como "una mujer blanca que hace música dancehall con un nombre artístico jamaicano"2. También podríamos subrayar la incertidumbre del equipo de dirección y presentación del programa musical El Bloque -Alicia Álvarez y Daniel Madjody-, al preguntar $^{3}$ a Somadamantina acerca de la imagen que acompaña a su último registro discográfico. Por último, es asimismo significativa la atención en forma de titular que la revista Mondo Sonoro dedica a la afirmación "El flamenco nos pertenece a todos y vamos a hacer lo que nos dé la gana con él", expresada por el dúo de artistas audiovisuales Los Voluble.

La distancia en el tiempo de estos ejemplos nos sirve, por un lado, para mostrar la multiplicidad estética, transmedia y transcultural de una escena musical tan rica como inasible; y, por otro, para ejemplificar distintas prácticas de apropiación, una acción ubicua e inherente al acto creativo.

Sin entrar a constituir una definición integral del término ${ }^{5}$, podríamos afirmar que, ya sea del flamenco contemporáneo o el trap experimental, al arte sonoro, la electrónica o la música académica actual, una parte muy significativa de la realidad musical española podría ser considerada como resul-

\footnotetext{
${ }^{1}$ Oswald de Andrade: "Manifiesto Antropófago", Revista de Antropofagia, año 1, n. ${ }^{\circ} 1,1928$, pp. 3 y 7.

${ }^{2}$ Niloufar Haidari: "Bad Gyal Wants to Be the Queen of Catalan Trap", Noisey, 1-6-2017 (https://noisey.vice.com/en_uk/article/43yg4q/bad-gyal-interview-catalan-trap-dancehall, consulta 22-1-2019): "a white woman making dancehall-influenced music under a Jamaican stage name". Traducción del autor. 2019).

${ }^{3}$ El Bloque, a partir de 3'07" (https://www.youtube.com/watch?v=Bor0wE8sBxs\&t=200s, consulta 23-2-

${ }^{4}$ Fernando Fuentes: "El flamenco nos pertenece a todos y vamos a hacer lo que nos dé la gana con él", Mondo Sonoro, 20-1-2019 (https://www.mondosonoro.com/entrevistas/los-voluble/, consulta 22-2-2019).

${ }^{5}$ Que consideramos bien realizada y expuesta, como primera de las veinticuatro expresiones definidas en Eduardo Navas, Owen Gallagher, xtine burrough (eds.): Keywords in Remix Studies, Londres, Routledge, 2017, pp. 14-23.
} 
tado de un proceso de apropiación. Esta escena múltiple se constituiría, entonces, en una suerte de palimpsesto en continua reconstitución y resignificación. No en vano, identidades, ideologías y expresiones de diverso origen convergen, de manera natural, aunque no exenta de discusión, hacia propuestas artísticas complejas y poliédricas, que son acusadas, según el caso, de practicar o ser resultado de dicha apropiación. Este término es percibido como un problema o un acto negativo y pernicioso ${ }^{6}$.

Sin duda, son muchos los matices éticos, estéticos y políticos que emergen cuando intentamos definir esta práctica, también concebible desde múltiples puntos de vista. Teniendo en cuenta expresiones y conceptos tan consolidados, inspiradores y heterogéneos entre sí como "cultura híbrida", umbral y distinción ${ }^{8}$ o "cuerpo impropio", entre otros, nos proponemos analizar el rastro intertextual -impropio e impuro- de varias creaciones ubicadas en el terreno del flamenco experimental y de la composición académica contemporánea.

Magnanimity (2018). Imagen de cubierta. Cristina Sanz "Somadamantina", Irene Royo (fotografia), Bea Rosell (maquilladora) ${ }^{10}$.

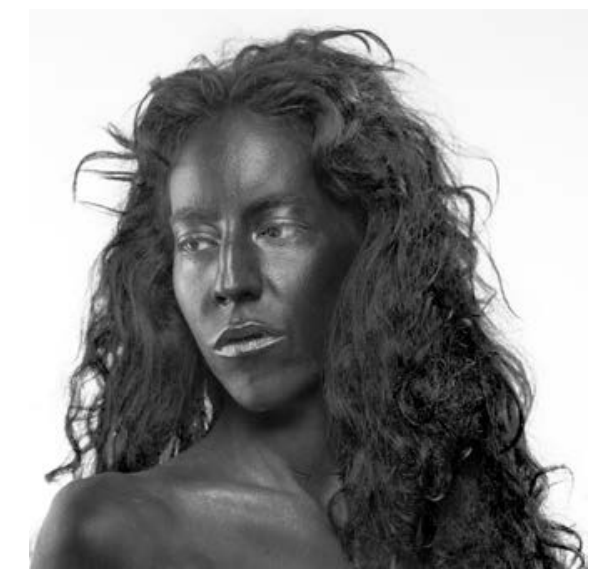

${ }^{6}$ Así lo entiende, por ejemplo, el periodista musical Víctor Lenore: "Tenemos un problema de apropiación cultural, pero no es culpa de Rosalía”, El Confidencial, 30-8-2018 (https://www.elconfidencial.com/ cultura/2018-08-05/rosalia-apropiacion-cultural-flamenco-fusion_1600138/, consulta 23-2-2019).

${ }^{7}$ Néstor García Canclini: Culturas híbridas. Estrategias para entrar y salir de la modernidad, México D. F., Grijalbo, 1990.

${ }^{8}$ Byung-Chul Han, autor surcoreano pero afincado en Alemania, define umbral como "una típica sensación liminar. El umbral es el tránsito a lo desconocido. Más allá del umbral comienza un estado óntico totalmente distinto. Por eso el umbral lleva inscrita siempre la muerte. [...] El umbral como lugar de transformación duele". La distinción la entiende como una "voz del otro [que] zozobra en el ruido de lo igual. [... L La poesía y el arte [y, desde nuestro punto de vista, también la música] están de camino a lo distinto. Su rasgo esencial son las ansias de lo distinto". Byung-Chul Han: La expulsión de lo distinto, Barcelona, Herder, 2017, pp. 57 y 101.

${ }_{9}^{9}$ Observado como "un aparato somático estratificado, denso, siempre intervenido por técnicas biopolíticas que al mismo tiempo le avasallan y le confieren potencia de actuar. El cuerpo no es naturaleza sino somateca, un archivo político de lenguajes y técnicas", Paul B. Preciado: Cuerpo impropio. Guía de modelos somatopoliticos y de sus posibles usos desviados, Texto introductorio, Sevilla, Universidad Internacional de Andalucía, 2011 (http://ayp.unia.es/index.php?option=com_content\&task=view\&id=678, consulta 18-1-2019).

${ }^{10}$ Reproducido con permiso de la artista. 
En todo caso, nos centraremos en creaciones con "punto de originación"11 español, aunque generadas desde contextos biográficos y estéticos dispares. Estas propuestas son el resultado de un comportamiento artístico que consideramos singularmente elocuente dentro de dos escenas musicales: la flamenca y la que protagoniza la creación académica, ambas entendidas en su dimensión contemporánea y experimental. Nuestro objetivo, con los estudios de caso escogidos, no es contemplar una posible definición del término apropiación, sino vaciarlo de sentido negativo, a través de un elogio que defiende su naturaleza de conditio sine qua non para que pueda darse la creación artística y musical.

Como premisa, partimos de la afinidad semántica que mantienen conceptos como impropio e impuro ${ }^{12}$ y su relación con la práctica intertextual, entendida, en palabras del compositor José María Sánchez-Verdú, como "la presencia de una obra anterior en una nueva (hipotexto e hipertexto) [...], como la sangre bajo una nueva piel, como las raíces de un nuevo árbol que se abre en flor" ${ }^{13}$. Ambos términos, a medio camino entre la ética y la estética, nos remiten al proceso orgánico que subyace no solo al devenir artístico sino, como también veremos, al modo en que percibimos, efectuamos, comunicamos o compartimos todo objeto cultural.

Finalmente, y a modo de aclaración metodológica, querríamos destacar el trabajo de Rubén López Cano ${ }^{14}$, cuyo estudio deliberadamente indefinido en torno al término apropiación nos ha servido de marco disciplinar e instigador, junto al del resto de autores que comentaremos en seguida.

\section{Deriva conceptual. Impurezas y f[r]icciones}

Cita, versión, cover, arreglo, montaje, bricolaje, alusión, préstamo, interpretación, mezcla, glosa, robo, intervención, deconstrucción, paráfrasis, reutilización o reciclaje. Como vemos, existe una cantidad inusitada de términos que, según

${ }^{11}$ Traducción literal de la expresión "point of origination", en Walter Mignolo: "Geopolitics of Sensing and Knowing On (De)Coloniality, Border Thinking, and Epistemic Disobedience", Postcolonial Studies, 14, pp. 273-283. Esta expresión debe vincularse a la teoría postcolonial del sociólogo argentino, conocido por su aforismo "I am where I think", en W. Mignolo: Local Histories/Global Designs. Coloniality, Subaltern Knowledges and Border Thinking, Princeton-Oxford, Princeton University Press, 2012, p. 89.

${ }^{12}$ Término que entendemos de manera polisémica, siguiendo tanto la estética de Vladimir Jankélévitch: Le pur et l'impur, París, Flammarion, [1960] 1998, como la de Jean-Noël Vuarnet: El discurso impuro, Barcelona, Ediciones Incorpore, 2018, y su aplicación expresa en lo flamenco, que analiza Cristina Cruces: Flamenco. Negro sobre blanco. Investigación, patrimonio, cine y neoflamenco, Sevilla, Editorial Universidad de Sevilla e Instituto Andaluz del Flamenco, 2018, pp. 325 y ss.

${ }^{13}$ José María Sánchez-Verdú: "Arquitecturas del eco (Reflexiones fragmentarias sobre música y tradición)", Sibila. Revista de Arte, Música y Literatura, 18, 2005, pp. 39-41; 41. No hemos utilizado aquí las referencias fundacionales de la teoría intertextual, de sobra conocidas y empleadas, sino una definición más próxima a los estudios de caso seleccionados.

${ }^{14}$ Rubén López Cano: Música dispersa. Apropiación, influencias, robos y remix en la era de la escucha digital, Barcelona, Musikeon, 2018. 
el período histórico, el ámbito disciplinar o el emplazamiento estético y político desde el que se genere cualquier dispositivo artístico, denominan un hecho tan connatural al proceso creativo como el de la apropiación. De hecho, y acercándonos a lo estrictamente sonoro, podríamos decir que nunca se dio ni existe paso, proceso o propuesta musical de la que dicha apropiación no formara parte. Su persecución o enarbolamiento, más allá de cuestiones jurídicas que no serán objeto de análisis en este trabajo, tienen que ver con la tensión que provoca una concepción errónea o poco pertinente de la propiedad en el terreno de lo artístico. Es decir, el aforismo inicial con el que se iniciaba este texto ("Solo me interesa lo que no es mío"), ofrece una lectura ambivalente: me interesa -me apropio de-lo que no es mío, siendo consciente -o creyendo serlo- de lo que es, efectivamente, mío o propio. Se da aquí una delicada confluencia entre ética, política y estética, obviamente asentada sobre una noción estática de términos como memoria, identidad y tradición, siendo todas ellas, como son, una ficción $-\mathrm{f}[\mathrm{r}]$ icción, si seguimos el juego propuesto por el MNCARS en el año 2000- o, incluso, puro fake $e^{15}$.

Ofrecidos a modo de muestrario, los ejemplos citados al inicio del texto nos sitúan, sin duda, ante una tensión o fricción provocada por los elementos que se ponen en relación: en el caso de Bad Gyal, su conocimiento y uso de los parámetros musicales propios del dancehall jamaicano, aún siendo una artista nacida en Vilassar de Mar (Barcelona); en el de Somadamantina, se trata del aparente blackface ${ }^{16}$ que evoca su cuerpo completamente maquillado de un profundo negro; si observamos la afirmación de Los Voluble, dicha tensión se encuentra en la desmitificación del flamenco, criticando su peligrosa patrimonialización. Estas actitudes aportan un factor perverso e impuro, respecto de una idea estática de género musical, cuyo estatus inicial es considerado casto e incorrupto. A modo de contextualización conceptual, podemos asumir que la fricción

se reinscribe $[\ldots]$ en el campo del juego del lenguaje y consiste en infinitas substituciones, superposiciones, remisiones e interferencias en el interior de un conjunto dado y cerrado. Así, las operaciones de fricción son teóricamente infinitas justamente porque su campo de acción es limitado, o sea, porque a diferencia del

${ }^{15}$ Siendo conscientes de que es extensa y muy consolidada la historiografía en torno a estos conceptos, ya de Nietzsche a Hobsbawm, entre otros, citamos algunas de las últimas referencias de gran interés, publicadas en castellano: Manuel García Carpintero: Relatar lo ocurrido como invención. Una introducción a la filosofía de la ficción contemporánea, Madrid, Cátedra, 2016; Raúl Rodríguez Ferrándiz: Máscaras de la mentira. El nuevo desorden de la posverdad, Valencia, Pretextos, 2018; Jorge Luis Marzo: La competencia de lo falso. Una historia del fake, Madrid, Cátedra, 2018.

${ }^{16}$ Maquillaje teatral con el que se intentaba conseguir el aspecto de los músicos y artistas afroamericanos, véase Eric Lott: Love and Theft. Blackface Minstrelsy and the American Working Class, Oxford-Nueva York, Oxford University Press, 2013. 
espacio indefinido pero inagotable de la episteme clásica, ese campo teórico carece ahora de un centro y, consecuentemente, de una jerarquía primordial que funde el juego de las fricciones ${ }^{17}$.

La apropiación podría localizarse, precisamente, en ese juego de jerarquías al que nos enfrenta toda creación contemporánea y toda propuesta que interrogue al espectador, convertido, desde ese momento, en coautor de la propia obra. En este sentido, y como afirma el rabino de origen franco-marroquí Mark-Alain Ouaknin: "El sentido de un texto [...] sobrepasa a su autor no ocasionalmente, sino para siempre: es por ello por lo que la comprensión no es una actitud únicamente reproductiva sino también y siempre una actitud productiva"18.

Nuestra deriva conceptual también nos lleva a transitar por uno de los elementos constituyentes de la identidad -concebida siempre como un imaginario social e ideológicamente construido- y, por tanto, de nuestra condición de espectadores/oyentes de un dispositivo artístico o musical dado. Dicho elemento es la memoria. En este sentido, lo impuro, esa f[r]icción de la que venimos hablando, entendida como consecuencia lógica y connatural al acto de apropiación, estaría causado, también, por el relato subalterno e incómodo de una "memoria minoritaria", según la define Rosi Braidotti, en una personal aplicación de la filosofia de Deleuze. Se trata de

una fuerza de recordación que no está sometida a priori en sus proposiciones al banco de datos centralizado. Este tipo de rememoración intensa, zigzagueante, cíclica y desordenada ni siquiera intenta recuperar información de una manera lineal. [...] Funciona como una capacidad de acción desterritorializadora que desacopla al sujeto de una localización unificada y centralizada ${ }^{19}$.

Entendidos como una oportunidad para profundizar en lo expuesto hasta ahora, los estudios de caso aquí analizados exigen, por parte del oyente, de una aceptación de lo distinto ${ }^{20}$ que cuestiona el relato histórico que ha servido para construir una memoria colectiva y, por tanto, una identidad social y cultural específica. En este sentido, la memoria minoritaria nos ayudaría a configurar una identidad dinámica, abierta al relato alterno, construido desde lo local y lo marginado. Sería una manera particular de adherirnos a lo que el curador peruano Miguel Ángel López observa en las prácticas artísticas "de oposición”: "serle infiel a la historia, traicionarla, tomar el control de su aparato narrativo" 21.

\footnotetext{
${ }^{17}$ Raúl Antelo: "La fricción, una alegoría de lo infraleve", F[r]icciones. Versiones del sur, Catálogo de la Exposición, Juan Manuel Bonet et al., Madrid, Museo Nacional Centro de Arte Reina Sofía, 2000, pp. 218-231.

${ }^{18}$ Mark-Alain Ouaknin: Elogio de la caricia, Madrid, Trotta, 2006, p. 19.

${ }^{19}$ Rosi Braidotti: Transposiciones. Sobre la ética nómada, Barcelona, Gedisa, 2009, p. 231.

20 "El rasgo esencial de las artes debe ser su ansia de lo distinto", como afirma Han: La expulsión..., p. 201

${ }^{21}$ Miguel Ángel López: Robar la historia. Contrarrelatos y prácticas artísticas de oposición, Santiago de Chile, Ediciones Metales Pesados, 2017, p. 16.
} 


\section{"Confieso que he robado" 22 : la remezcla infinita, de Niño de Elche a Flamante}

Además de ser una expresión colosal de lo expuesto hasta ahora, el flamenco es también una manifestación artística mantenida y alimentada por una ininterrumpida práctica intertextual. De hecho, su aprendizaje, interpretación y creación se encuentran fundamentadas y, en su caso, legitimadas, por una ideologizada y racializada "memoria de la sangre". La práctica flamenca muestra un sentido de pertenencia o nacencia en el que cada paso musical, desde una óptica ortodoxa y aparentemente canónica, pretende recordar o recuperar un paso anterior y precedente, de mayor rango artístico y con autoría legitimadora. Como afirma Pedro G. Romero: "El flamenco es un arte anacrónico [...] también por ser capaz de evocar dos temporalidades a la vez, la del inmediato presente y otra que se pierde en los orígenes de no se sabe qué, en un tiempo mítico, pasado y futuro a la vez"23.

En este sentido, podemos afirmar que el análisis de casi cualquiera de las propuestas protagonizadas por Francisco Contreras, Niño de Elche (Elche, 1985), podría centrar la atención de nuestro trabajo. Su opus musical es, sin duda, un ejemplo radical de hiper/intertextualidad, impureza, perversión y f[r]icción en la escena contemporánea. Desde una opción estética en la que convergen, entre otros elementos, el anarchivo ${ }^{24}$, la contramemoria ${ }^{25}$ y una conciencia ficcional que navega entre el sarcasmo y lo fake, el excantaor

\footnotetext{
${ }^{22}$ Extraído de Niño de Elche: "Confieso que he robado", El Mundo, 17-9-2018 (https://www.elmundo. es/papel/cultura/2018/09/16/5b9e6d92e2704e98528b461d.html, consulta 23-2-2019).

${ }^{23}$ Pedro G. Romero: "Gran magna ANTOLOGÍA, historia, memoria, rito y geografía DEL canto flamenco-andaluz, mundo y forma del CANTE gitano y archivo y tesoro del FLAMENCO original, antiguo, jondo y HETERODOXO", en Niño de Elche, título homónimo, Madrid, Sony Music, 2018, pp. 1-3; 2.

24 "Destinado a producir campos de relación dinámicos e inéditos, donde las fuentes iconográficas a las que alude el archivo, más allá de su cualidad documental, buscan desestabilizar el significado original para recontextualizarlo de nuevo", según afirma Yolanda Guasch: Arte y archivo 1920-2010: genealogías, tipologías y discontinuidades, Madrid, Akal, 2011, p. 227. Por "afinidad" estética, en lo que a la noción radical de cuerpo que ofrece, nos resulta de interés rescatar aquí la definición de "anarchivo" ofrecida por Duen Xara Sacchi, como parte del análisis de la exposición Anarchivo sida, celebrada en Tabakalera (San Sebastián) en 2016: "El Anarchivo es un archivo anárquico por definición, un archivo que está estallado, un archivo que está hecho de retazos, un archivo queer, de lo raro, un archivo de la vergüenza, del armario, de la exposición, del contagio, de la transmisión humano-humano, un archivo anal también, un archivo no solo inscripto en las políticas de la lengua o el lenguaje articulado, un archivo animal, un archivo de las diferentes formas del duelo, un archivo sobre cómo la sangre, el semen y la piel, los órganos soberanos disciplinares han determinado las políticas y las resistencias identitarias hegemónicas y disidentes occidentales", Duen Xara Sacchi: "Un Anarchivo... Exposición en Tabakalera", El Estado Mental, 19-6-2016 (https://elestadomental.com/diario/un-anarchivo).

25 "Countermemory starts with the particular and the specific and then builds outward toward a total story. [...] Looks to the past for the hidden histories excluded from dominant narratives". Georges Lipsitz: Time Passages: Collective Memory and American Popular Culture, Minnesota, University of Minnesota Press, 1995, p. 213.
} 
- como se autodenomina- se sitúa en continuo estado de crisis tanto ontológica como propiamente artística. Con esta actitud, el Niño de Elche busca incesantemente el desplazamiento, también del oyente, a través de una experimentación iconoclasta. Para llegar a ella, ha sido y es imprescindible el contacto con otros disidentes artísticos ${ }^{26}$. Cada una de las iniciativas artísticas que acomete es una oportunidad para remezclar, montar, deshacer y rehacer nuevos vínculos intertextuales. Cuando se ubica en el ámbito del flamenco, dicha actitud lo lleva a producir dispositivos musicales críticos y profundamente controvertidos que lo sitúan en esa f[r]icción de la que hablábamos al comienzo de nuestro texto.

Por ejemplo, su proyecto Sí, a Miguel Hernández-SAMH (2013) ${ }^{27}$ toma una figura de la memoria mayoritaria para construir un relato propio contra una sociedad capitalista y neoliberal del bienestar que concibe al poeta de manera superficial y acrítica. Asimismo, y desde una opción contracultural, irreverente, subalterna y extremadamente crítica, Niño de Elche ofrece su más reciente Gran magna ANTOLOGÍA, historia, memoria, rito $y$ geografía DEL canto flamenco-andaluz, mundo y forma del CANTE gitano $y$ archivo y tesoro del FLAMENCO original, antiguo, jondo y HETERODOXO (Sony Music, 2018). Este registro es, sin duda, y como ya puede deducirse por el título, una oportunidad, quizás, para decolonizar lo flamenco desde la herramienta conceptual que nos ofrece la noción estética de lo fake, entendido como "ficción impostada [...] ficción con apariencia de verdad que se infiltra en los dispositivos de transmisión de información y se camufla bajo la apariencia de un género familiar y reconocible. Competencia de la política, de un determinado activismo que intenta incidir en la conciencia pública de un receptor" 28 .

La simple lectura de los números que constituyen esta Antología ${ }^{29}$ deja ver que son múltiples las opciones de análisis que ofrece desde la perspectiva intertextual. De entre ellas, querríamos destacar dos.

La primera es aquella que toma como referencia estructural y sintáctica una pieza anterior, en la que es obvia la referencia musical establecida, al menos en un primer nivel analítico y desde una sencilla escucha. En este sentido, "Rumba y Bomba de Dolores Flores" es un ejemplo paradigmático: a partir de una pieza musical presumiblemente inocua como "La Bomba

${ }^{26}$ Como los que componen www.bulos.net, junto a Raúl Cantizano y Santi Barber, el colectivo Zemos98 o el artista Pedro G. Romero.

${ }^{27}$ http://www.ninodeelche.net/si-a-miguel-hernandez/ (consulta 25-9-2017).

${ }^{28}$ J. Fontcuberta, en Jorge Luis Marzo: La competencia de lo falso. Una historia del fake, Madrid, Cátedra, 2018, 159 .

29 2. "Saetas de San Juan de la Cruz", 5. "Coplas mecánicas de Juan de Mairena" -especialmente relevante por su puesta en escena en el XXV Festival Sónar (2018) y por el documental Coplas mecánicas, que Víctor Hugo Espejo realizó a partir de dicha interpretación-, 6. "Saeta del Mochuelo con la Mariana seguido de Plazoleta de Sevilla en la noche del Jueves Santo" o 16. "Tanguillos de Cádiz de 1947", por ejemplo. 
Gitana"30, Niño de Elche crea una pieza con múltiples capas de lectura. En la estrictamente compositiva, existe una cita literal de las dos secciones melódicas y líricas en las que se divide la canción original de Lola Flores (identificadas con los versos "Esta es la bomba gitana...", melodía que podríamos denominar A, y “¿Usted tiró la bomba, la bomba quién tiró?”, melodía B), aunque con un trabajo tímbrico que incluye el uso de sintetizadores. Ambas rumbas avanzan de forma casi idéntica hasta el 1'50" -minuto 2'05”, en el caso de la Antología-, cuando Lola Flores y Niño de Elche realizan una cuenta atrás para la explosión de la bomba. Tras ella, Lola Flores retoma y repite las melodías A y B para concluir con un fade out. Niño de Elche, sin embargo, interviene la melodía B y se instala en ella, aprovechando la pregunta “¿Quién tiró la bomba?” para, ya sin acompañamiento musical y con una interpretación vocal extenuada, interpelar al oyente con “¿Usted?”. Este giro semántico nos ubica en el centro narrativo de la canción, dándonos la oportunidad de interpretar de nuevo la letra, esta vez con una carga política inaudita que ahora podría afectar, incluso, a nuestra recepción de la primera versión. Dicho giro se ve reforzado, además, por la pieza visual que realizó el colectivo Los Voluble ${ }^{31}$. En ella convivían secuencias de las Guerras de Irak con imágenes de celebraciones caseras en diversas comunidades y bombardeos reales. El vídeo está dedicado, además, a la polémica figura de Claude Eatherly ${ }^{32}$.

Un giro intertextual más lo efectúa el artista -junto a Pedro G. Romero- en el libreto de esta Antología. En él se nos explica que la "Dolores Flores" a la que alude el título no es exactamente Lola Flores, sino que alude al sobrenombre con el que el actor Mario Montez ${ }^{33}$ intervino en la controvertida película Flaming creatures (Jack Smith, 1962-63). Según afirma

\footnotetext{
${ }^{30}$ Firmada por la artista Lola Flores y Fernando de León, lanzada en 1974, por Belter.

${ }^{31}$ Disponible en https://www.facebook.com/ninodeelche/videos/1612416688846087/. La actividad audiovisual de Los Voluble debe entenderse, también, desde esta noción de remezcla, resignificación y recreación que caracteriza las propuestas analizadas en este artículo. Y no solo su producción estrictamente artística, que puede rastrearse en el siguiente enlace, http://www.voluble.net/, sino también su actuación como parte del colectivo Zemos98, cuyo Festival, celebrado en Sevilla entre 1998 y 2008, sirvió como terreno de experimentación y reflexión en torno a asuntos muy ligados a la noción intertextual que venimos analizando. Así fue en la edición de 2008, titulada de forma genérica Código Fuente: la Remezcla, que dio pie a la publicación de un volumen, Felipe G. Gil, Mar Villaespesa (eds.): Código Fuente: la remezcla. Una narración colectiva a partir de los Encuentros Regreso al futuro, Festival Zemos98-10. ${ }^{a}$ edición, Sevilla, Hapaxmedia, Asociación Cultural Comenzemos Empezemos-Instituto Andaluz de la Juventud-Universidad Internacional de Andalucía, 2009.

32 Piloto del comando que dio el all-clear para el histórico bombardeo de la ciudad de Hiroshima y que, tras el ataque y al finalizar el conflicto, se convirtió en un miembro activo del movimiento antibelicista.

${ }^{33}$ Nombre artístico, a su vez, de René Rivera (Ponce, Puerto Rico, 1935-Florida, 2013). Véase Marc Siegel: “...For MM”, Criticism, 56, 2, 2014, pp. 361-374.
} 
Pedro G.: "[Montez] En 1968, seis años antes de la grabación oficial, se jactaba de hacer versiones de la Bomba de Lola Flores en la Factory neoyorquina, con la guitarra de Lou Reed y el órgano de John Cale".

La Antología nos muestra otro tipo de relación intertextual, menos obvio, pero igualmente simbólico y con una carga política sujeta a nuestra propia capacidad de memoria. Se trata de "Lekeitio n. ${ }^{\circ} 5$ ", concebida a partir de los versos del cantautor vasco Mikel Laboa, puesta en escena en el marco del proyecto Suena Guernica ${ }^{34}$ e interpretada ad hoc junto a los temas "Europa muda" y "Destruidnos juntos" 35 . Sin entrar a analizar el relato que música y poesía establecen a través de la lectura e interpretación en castellano de los versos de Laboa, resulta interesante la elección sonora con la que Niño de Elche canta la expresión “iQue no!”, que cubre tres cuartas partes de la canción. Con el sencillo y pertinaz acompañamiento de Raúl Refree $^{36}$ en armónicos vinculados al círculo de La Mayor, el cantaor repite esta expresión, en una suerte de negación incrédula ante la catástrofe social y humanitaria de un bombardeo. Su voz alcanza a cada paso mayor volumen, en forma de glissando ascendente aunque fragmentado, para concluir con un “¡No!" de 15 segundos, sobre un Do agudo heterofónico y dramático. Este momento establece un nodo intertextual que resignifica la canción, pues recuerda a una sirena antiaérea, que comienza a sonar más tímidamente hasta que ensordece a todo aquel que la percibe. El timbre que alcanza Niño de Elche, con esa nota aguda final, nos avisa de que el bombardeo persiste hoy, en cualquier otro lugar.

La "remezcla infinita", a la que aludíamos al comienzo de este epígrafe, lleva al extremo tanto la noción intertextual como la responsabilidad hermenéutica del oyente/espectador. Además, expande las posibilidades de nuestro análisis hacia otras propuestas igualmente subalternas, en las que este procedimiento es aún más evidente. Más allá de la abundante literatura que existe en torno a la remezcla -incluida en los denominados "remix studies"37-, tomaremos como referencia la aplicación que realiza Rubén

\footnotetext{
${ }^{34}$ Producido por Radio 3-Radio Nacional de España, y ya analizado en parte de nuestro texto en torno a la presencia de la Guerra Civil, como motivo artístico, estético o musical, en la escena española actual (Ordóñez, 2019).

${ }^{35}$ Canciones que formaron parte del disco Para quienes aún viven (Superball Music, 2017), realizado por Niño de Elche junto al grupo de rock instrumental progresivo Toundra, todos ellos bajo el sobrenombre de Exquirla.

${ }^{36}$ Productor artístico de la Antología, junto al propio cantaor.

${ }^{37}$ Sin entrar a realizar un análisis pormenorizado del estado de la cuestión, podría destacarse el pertinente estudio de Lawrence Lessig: Remix. Making Art and Commerce Thrive in the Hybrid Economy, London, Bloomsbury, 2008, pp. 76 y ss. Aquí, Lessig subraya los valores de comunidad y educación que aporta la práctica de la remezcla, al aprovecharse del nuevo significado que se construye a través del uso de una referencia pasada. También cabría señalar la definición, de corte más técnico, que aporta David J. Gunkel: Of Remixology. Ethics and Aesthetics after Remix, Cambridge, Massachusetts \& Londres, The MIT Press,
} 
Díaz del término definido por Eduardo Navas, por tratarse de la más cercana al contexto en el que surgen los estudios de caso seleccionados. Según Díaz, la remezcla debe concebirse como "el hecho de tomar samples de material preexistente para combinarlo y transformarlo en nuevas formas según el gusto personal" 38 . En cualquier caso, se trata de una herramienta que facilita el uso de un material grabado con anterioridad. En ese sentido, destacaremos dos propuestas marginales, pero que ejemplifican un grado extremo de apropiación e impureza.

Se trata, por un lado, de la obra sonora de ELEE feat. Een Pianist? ${ }^{39}$. El artista malagueño nos sitúa en el terreno del arte sonoro. Como él mismo afirma, la manipulación que efectúa del timbre y los componentes vocales y estructurales de ciertos samples flamencos viene provocada por su consideración como parte de un abanico amplio de músicas

fuertemente asociadas a movimientos culturales localizados y con clara vocación reivindicativa de raíces populares que, o fueron marginadas en su momento, o que surgieron como voz de protesta ante la intolerancia, el racismo o la xenofobia. Pero sobre todo, y ya desde un punto de vista netamente sonoro [...] son géneros musicales que se ofrecen a la manipulación digital con un mayor grado de sugestión que otros ${ }^{40}$.

Esta "manipulación digital" es la que Elee feat. Een Pianist? emplea en los EPs Nueva Antología del Cante Jondo $(2018)^{41}$ y Duende Negro (Discos Victoria, $2018)^{42}$, que el propio autor califica como "Flamenco degenerado".

En segundo lugar, y en esta misma línea de manipulación sonora, pero con una manifiesta actitud contestaria y mayor aproximación a las músicas urbanas, se encuentra Flamante, artista afincado en Granada. Su producción

2016, pp. 15 y ss. El trabajo que consideramos de mayor interés, tanto en su contenido como en el formato que emplea, es el de E.Navas, O. Gallagher, x. burrough (eds.): Keywords in Remix Studies... citado anteriormente, que ofrece una revisión más específica y actualizada del anterior E. Navas, O. Gallagher, x. burrough (eds.): The Routledge Companion to Remix Studies, Londres, Routledge, 2015. Es obvio que este tipo de prácticas acepta también análisis como el que efectúa Nicholas Cook: "Beyond Music: Mashup, Multimedia Mentality, and Intellectual Property", The Oxford Handbook of New Audiovisual Aesthetics, John Richardson, Claudia Gorbman, Carol Vernallis (eds.), Nueva York, Oxford University Press, 2013, pp. 53 76. A pesar de lo interesante que puede resultar su aplicación a la noción de "autoría colectiva", tan polémica en la práctica del flamenco, se aleja, por ahora, del objetivo de este trabajo.

${ }^{38}$ Así emplea Rubén Díaz la definición que Eduardo Navas da al término, en R. Díaz: "nosotros, siempre nosotros... más algunos amigos", Código Fuente: la remezcla. Una narración colectiva..., p. 11.

${ }^{39}$ Aunque se presenta con doble sobrenombre, ambos pertenecen a la misma persona.

${ }^{40}$ Comunicación personal con Een pianist?, vía e-mail, 31-1-2019.

${ }^{41}$ Que integra los títulos "Fragmento Alegrías de la muerte", "Fragmento de Rito y Misterio de la Soleá", "Fragmento de Intersección Rondeña" y "Malagueña Oriental" (https://soundcloud.com/flamencodegenerado/sets/nueva-antologia-del-cante, consulta 23-2-2019).

${ }^{42}$ Constituido por los tracks "Zapateado", "Cantes Agujeteados sin Voz", "Quejío", "Tientos", "Martinete y Granaína” y "Responso", https://discosvictoria.bandcamp.com/album/duende-negro (consulta 232-2019). 
discográfica incluye Por tu mala cabeza (2017) ${ }^{43}$ y FlamanteRMX (2017), un "proyecto sonoro que propone la eclosión auditiva de badanas musicales de actitud punk y deje jondo" ${ }^{44}$. A estas referencias, se suma el trabajo experimental Estudio de bajo eléctrico y dispositivo móvil HTC sobre Antonio Mairena $(2018)^{45}$, que toma el icono mairenista como referencia sonora y visual.

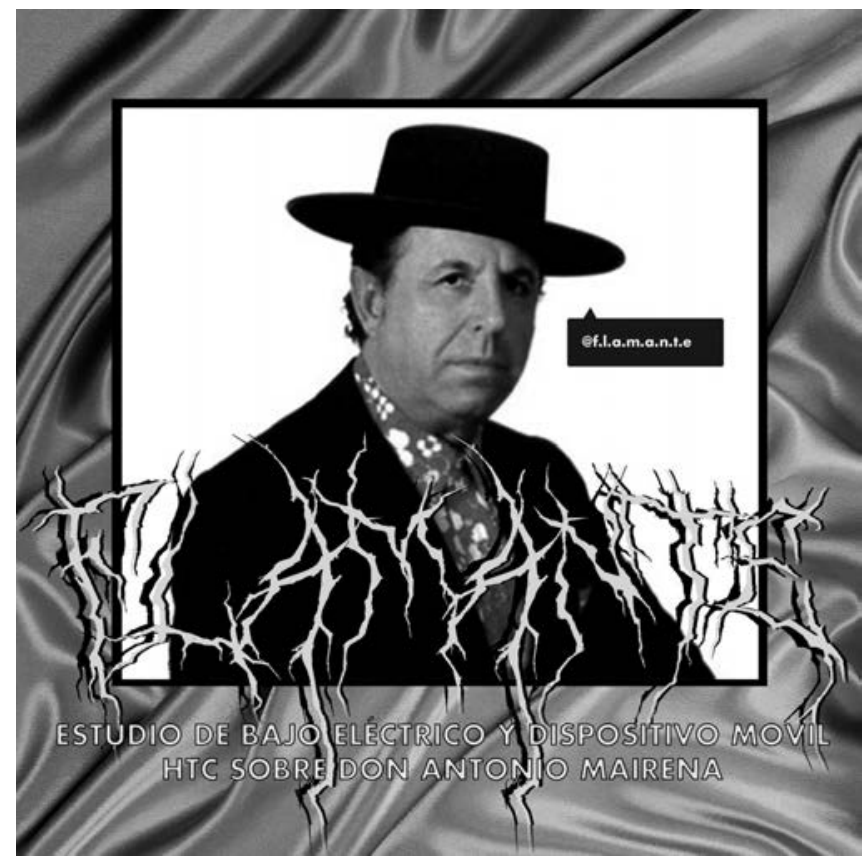

Flamante, Estudio de bajo eléctrico y dispositivo móvil HTC sobre Antonio Mairena (2018)

En ambas propuestas, generadas desde posturas estéticas distintas pero con procesos digitales y técnicos similares, existe una clara apertura hacia lo distinto, es decir, una actitud genéticamente impura que emplea un cierto "código fuente flamenco" para crear también, y de la misma manera que plantea Niño de Elche, una lectura iconoclasta y radicalmente impropia.

${ }^{43}$ Que incluye piezas como "GLICHTEA (la paquera de Jerez_Bulería)" o "Bns_ON VAPOR f.l.m.n.t (slowBULERIA)", https://flamante.bandcamp.com/album/por-tu-mala-cabeza (consulta 23-2-2019).

${ }^{44}$ Este trabajo muestra un remix a partir de la voz del cantaor flamenco Juan Moneo el Torta (Jerez de la Frontera, 1952-Sanlúcar de Barrameda, 2013) y piezas musicales de otros grupos musicales como Compro Oro o La URSS, véase https://flamante.bandcamp.com/album/f-l-a-m-a-n-t-e-rmx (consulta 23-2-2019).

45 Se puede consultar https://lamante.bandcamp.com/album/estudio-de-bajo-el-ctrico-y-dispositivo-movil-htc-sobre-antonio-mairena (consulta 23-2-2019).

${ }^{46}$ Reproducido con permiso del autor. 


\section{Diálogos expandidos, entre Lorca y la creación académica contem- poránea}

El relato incómodo y, al mismo tiempo, cautivador, paródico y sarcástico de Niño de Elche o Elee feat. Een pianist? es compartido por otros artistas, desde una actitud menos beligerante, aunque igualmente crítica y contestataria con el canon que rige cualquier escena musical.

Si nos situamos en el contexto de la creación académica, existe un ejemplo paradigmático: el compositor Mauricio Sotelo (Madrid, 1961), cuya obra "se define, externamente, por un cultivo sistemático de la impureza, es decir, de la combinación de lenguajes o de elementos heteróclitos, e internamente por un cuestionamiento continuo de los códigos" 47 .

Efectivamente, y si nos acercamos al catálogo compositivo de Sotelo, su creación está indefectiblemente ligada a una noción simbólica y estética de lo impuro. Dicha impureza se descifra como una atracción constante hacia la alteridad, ese "otro" que, en su caso, aparece encarnado en la voz flamenca del cantaor Enrique Morente (Granada, 1942-Madrid, 2010). El proceso compositivo que desencadena el análisis tímbrico de la voz morentiana y el marco poético y conceptual que lo justifica ${ }^{48}$ halla en la ópera El Público un ejemplo culminante ${ }^{49}$. Con libreto de Andrés Ibáñez (Madrid, 1961), El Público. Ópera bajo la arena, en cinco cuadros y un prólogo (2015), fue compuesta a partir de la pieza teatral homónima escrita por Federico García Lorca (Granada, 1898-1936) en torno a 1930, en New York, y completada en 1936, pocos meses antes de su asesinato. En una creación escénica como El Público existen múltiples aperturas al vínculo intertextual. Analizar sus matices excedería con creces los objetivos del estudio que aquí presentamos, por esta razón, nos quedaremos con aquellas que buscan reforzar una noción de lo alterflamenco -término que remezclamos con el que

\footnotetext{
${ }^{47}$ Andrés Ibáñez: "Mauricio Sotelo en siete piezas", Mauricio Sotelo: De oscura llama, Madrid, INAEM-ANEMOS, 2009, pp. 18-22; 18.

${ }^{48}$ Estudiado por Germán Gan Quesada: Mauricio Sotelo. Música extremada. Programa general del XXIV Festival de Música de Canarias, Las Palmas de Gran Canarias, Festival de Música de Canarias, 2008, pp. 308-347; Pedro Ordóñez Eslava: La creación musical de Mauricio Sotelo y José María Sánchez-Verdú. Convergencia interdisciplinar a comienzos del siglo XXI, Granada, Universidad de Granada, 2011; id.: "Postespectralismo(s) musical(es) en la creación contemporánea española. (Su)pervivencias del último relato compositivo", Revista de Musicología, XL, 1, 2017, pp. 19-46.

${ }^{49}$ Aunque excede los límites propuestos para este trabajo, citaremos también un trabajo más reciente en el catálogo de Mauricio Sotelo por su relevancia. Nos referimos a su participación en Flamenco envisioned, un proyecto promovido y realizado por el Trío Arbós, en el que varios compositores aluden, imitan o hacen referencia a lo flamenco desde cada uno de sus propios lenguajes creativos (http://www. cndm.mcu.es/es/proyecto-europa/trio-arbos-rafael-de-utrera-cantaor/domingo-3-febrero-2019-1400, consulta 27-2-2019).
} 
sintetiza la hermenéutica cultural del curador francés Nicolas Bourriaud ${ }^{50}$ y expandir el abanico de ilusiones sonoras hacia nuevos horizontes en la escucha.

Más allá del uso deliberado de instrumentos propios del género dentro de la plantilla orquestal ${ }^{51}$, gran parte de la ópera muestra un comportamiento flamenco. Desde el punto de vista compositivo, podemos percibirlo a través de indicaciones como "Ritmo sordo por bulerías", "Aire de bulería" (Cuadro I, Escena I, c. 113 y c. 252, respectivamente) o "Soleá" (Cuadro III, Escena I, c. 323 y ss.). Asimismo, también se da un uso deliberado de dos cantaores y un bailaor flamencos para representar personajes fundamentales del libreto ("Caballos primero, segundo y tercero", respectivamente $)^{52}$.

Desde un punto de vista conceptual, llama la atención el uso que Sotelo realiza del apellido Morente. A lo largo de la partitura, inserta esta palabra como indicación de carácter y, al mismo tiempo, como ofrenda musical a la figura del cantaor, en una suerte de intertextualidad velada al oyente, aunque necesariamente "interpretada" por la orquesta. Así ocurre con "Morente-Lorca" (Cuadro III, Escena 1. a, c. 443) ${ }^{53}$ o con "morente agonizante" y "morente intenso". Ambas expresiones afectan al canto del personaje "Desnudo rojo" (Cuadro IV, Escena única, cc. 8 y 14, respectivamente).

La Ópera bajo la arena de Mauricio Sotelo se apropia del componente artístico, corporal, musical y político del flamenco para construir una arquitectura experimental y dramática, a partir de una figura emblemática de la memoria histórica colectiva y hegemónica como Federico García Lorca. Sin embargo, lo hace desde una perspectiva subalterna, puesto que escoge una obra controvertida y profundamente convulsa como El Público5. De hecho, en esta obra teatral "no es difícil leer una denuncia de la resistencia a representar la verdad del amor homosexual en la escena teatral del momento, sin por ello dejar de interrogarse

\footnotetext{
${ }^{50}$ Nicolas Bourriaud: Altermodern. Tate Triennial, Londres, Tate Publishing, 2009.

${ }^{51}$ De la que forman parte la guitarra flamenca y un set de percusión con presencia específica del cajón.

${ }^{52}$ La presencia corporal de estos tres elementos en el relato artístico de la ópera y la dimensión política que aportan ya han sido analizadas en P. Ordóñez Eslava: "Lorca Unchained: Mauricio Sotelo's El Público and the (New) Spanish Contemporary Opera", Contemporary Music Review, vol. 38, 1-2, 2019, pp. 76-93.

${ }^{53}$ También hacia el final del Cuadro III aparece en la partitura la indicación "Gagaku" (c. 1031), en una clara referencia al género musical de origen japonés, con la que Sotelo incide en el carácter de la interpretación. Compositivamente, demanda el uso en la percusión del crótalo, entre otros gestos sonoros.

${ }^{54}$ Tras la sugerencia expresa que le realizó el entonces director del Teatro Real, Gerard Mortier.
} 
acerca de la posibilidad de determinar la verdad del deseo en general" 55 . Efectivamente, podríamos decir que de una práctica impura como la de Sotelo, emergen la naturaleza híbrida y la actitud insurrecta inherentes a lo flamenco ${ }^{56}$.

Durante los días en que se representaba El Público en el Teatro Real de Madrid, fueron celebradas varias actividades paralelas que pretendían, entre otras cosas, mostrar las concomitancias estéticas, poéticas y sonoras que la figura de Lorca podía inspirar. Una de ellas la protagonizó Rocío Márquez (Huelva, 1985), cantaora que, junto al colectivo Proyecto Lorca ${ }^{57}$, ofreció su particular apropiación de las Canciones populares que el poeta grabara junto a la Argentinita en 1931. En forma de suites, Márquez y Proyecto Lorca transitaron por "Nana de Sevilla", "Anda, Jaleo" y "Sones de Asturias" 58 , en un contexto tímbrico decisivamente imbuido de las técnicas extendidas propias del lenguaje académico contemporáneo. Como ejemplo, "Yo que soy contrabandista", de la ópera El poeta calculista (1805), escrita por el tenor y compositor sevillano Manuel García (0'45”-1'42”) y “Olé” (1962), de John Coltrane (4’35”-5’27”), aparecen de manera expresa entre algunas de las referencias que ofrece la "Suite II. Anda jaleo". Dichas referencias se encuentran enumeradas, además, en el libreto de Firmamento, y son fácilmente perceptibles en una escucha mínimamente activa. En la línea de investigación que venimos desarrollando, es preciso decir que la obra de Rocío Márquez merecería atención aparte y específica. Desde su andrógina recreación del cantaor José Tejada Martín "Pepe Marchena" en El Niño (Universal, 2014) o los registros Firmamento (Universal, 2017) y Diálogos de viejos y nuevos sones (Universal, 2018), la cantaora busca la resignificación de ciertos cánones estéticos e ideológicos vinculados a lo flamenco. Márquez culmina este proceso creativo con su último trabajo, Visto en el Jueves (Universal, 2019), en el que remezcla cantes y canciones halladas en el mercado homónimo sevillano.

\footnotetext{
${ }^{55}$ Antonio Monegal: "Una revolución teatral inacabada", Federico García Lorca: El Público. El sueño de la vida, Madrid, Alianza Editorial, [2000] 2009, pp. 7-42; 24-25.

${ }^{56}$ Como demuestran, entre otras, las publicaciones de Francisco Almazán: "La escalada del Flamenco", Triunfo, 402, 1970, p. 45; José Luis Ortiz Nuevo: Pensamiento político en el cante flamenco: antología de textos desde los orígenes a 1936, Sevilla, Editoriales Andaluzas Unidas, 1985; Alfredo Grimaldos: Historia social del flamenco. Barcelona, Ediciones Península 2010; P. Ordóñez Eslava: "Qualities of Flamenco in the Last Francoism: Between the Renaissance and the Conscience of Protest", Music and Francoism, Gemma Pérez Zalduondo, Germán Gan Quesada (eds.), Turnhout, Brepols Publishers, 2013, pp. 265283; Juan Vergillos: "Flamenco y República: la historia del Chato de las Ventas", 2014 (http://vaivenesflamencos.com/post/73392472141/fragmento-del-espect\%C3\%Alculo-flamenco-y-rep\%C3\%BAblica, consulta 26-2-2019).

${ }^{57}$ Constituido, en aquel momento, por Daniel Borrego al piano, Juan M. Jiménez en los saxofones y Antonio Moreno como percusionista.

${ }^{58}$ Piezas incluidas en el registro discográfico Firmamento (Universal, 2017), dirigido artísticamente por Pedro G. Romero y producido por Raúl Refree.
} 
El penúltimo giro apropiacionista en la órbita lorquiana de El Público es el que efectúa el grupo Lagartija Nick. Su Crimen, sabotaje y creación (Universal, 2017) -términos muy ligados al habitual proceso compositivo, por otra parte-, incluye la pieza "El teatro bajo la arena", con texto íntegro de Jesús Arias (Granada, 1963-2015), hermano del vocalista y líder del grupo, Antonio Arias. Aunque no existe vinculación melódica o musical expresa al cancionero lorquiano, Lagartija alude aquí al proyecto dramático del Lorca surrealista, del poeta agitador sin máscaras. Teniendo en cuenta lo expuesto por Julio Ogas ${ }^{59}$, podemos descifrar aquí la intención deliberada y el uso poético y político consciente que Jesús Arias demuestra al usar el conocido sintagma lírico de Lorca como título para su canción.

Un caso emblemático dentro de la creación académica contemporánea, -y aún más intenso, en lo que a la conciencia intertextual se refiere-, es el que encarna el compositor José María Sánchez-Verdú (Algeciras, 1968).Tras estas dos primeras décadas del siglo XXI, podemos decir que el compositor andaluz escribe y defiende su propuesta sonora con una sólida madurez compositiva. Su imaginario artístico incorpora un aparato referencial rico en incitaciones multidisciplinares y estilísticas, dando lugar a uno de los catálogos más exuberantes de la escena musical contemporánea. Más allá de la noción de palimpsesto ${ }^{60}$, fácilmente apreciable en su corpus conceptual y musical, Sánchez-Verdú genera una obra musical poliédrica en la que el vínculo intertextual constituye "un aspecto importante y constante: la presencia de una obra anterior en una nueva (hipotexto e hipertexto) y los distintos grados de relación que se pueden presentar en ellas - cita, transformación, transestilización, continuación, etc.- son un tema fascinante que he tratado de recoger y solucionar" ${ }^{61}$.

A modo de ejemplo, podemos citar piezas como Plaine de dueil ${ }^{62}$ (Cuarteto de cuerda n. $^{\circ}$ 6) (2000), Déploration sur la mort de Johannes Ockeghem (2000-2001), Machaut-Architekturen I-V ${ }^{63}$ (2003-2005) y creaciones más

\footnotetext{
59 Julio Ogas: "El texto inacabado: tipologías intertextuales, música española y cultura", Creación musical, cultural popular y construcción nacional en la España contemporánea, Celsa Alonso (ed.), Madrid, ICCMU, 2010, pp. 233-251.

${ }^{60}$ Analizada en P. Ordóñez Eslava: "La creación musical como palimpsesto estético: poética y proceso compositivo en la obra de José María Sánchez-Verdú", Revista de Musicología, XXXIII, 1-2, 2010, pp. 195-209.

${ }^{61}$ J. M. Sánchez-Verdú: "Arquitecturas del eco...", p. 41.

${ }^{62}$ En la que toma como referencia poética y sonora la chanson homónima de Josquin des Prez.

${ }^{63}$ Las piezas I y V, precisamente, fueron estrenadas en un proyecto estrenado por el Ensemble Taller Sonoro en 2004, en el que se que promovía el trabajo de recreación de José Manuel López López (Madrid, 1956) y Elena Mendoza (Sevilla, 1973), junto al propio Sánchez-Verdú, a partir de la Misa de Nôtre Dame de Guillaume de Machaut. Véase P. Ordóñez Eslava: Sevilla y la música contemporánea. Estudio de una historia viva, Sevilla, ICAS-Excmo. Ayuntamiento de Sevilla, 2014.
} 
complejas como Libro de las Estancias ${ }^{64}$ (2007). También podríamos subrayar su más reciente Terrains vagues (2017-2018), en la que "fragmentos, estratos, polilecturas y diferentes perspectivas de la chanson [Cueurs désolez de Pierre de la Rue] han permanecido en este sentido como cristales de tiempo y fragmentos de espacio" ${ }^{\prime 65}$.

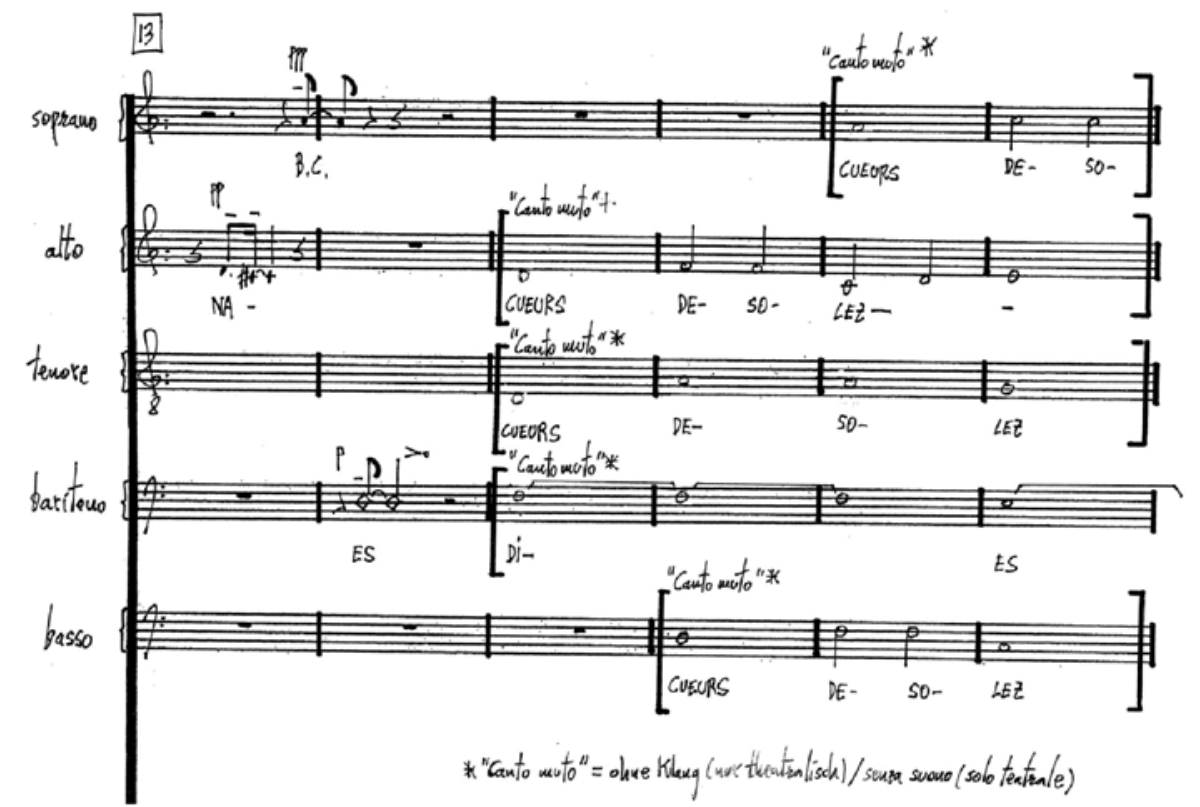

José María Sánchez-Verdú: Terrrains vagues (2017-2018), quinteto vocal, cc. 13 y ss. (c) 2018 by Breitkopf \& Härtel, Wiesbaden

La intertextualidad funciona en la obra de Sánchez-Verdú como una apertura al otro, como una mirada/escucha en la que el compositor se proyecta en forma de "caja de resonancia en la que el otro se libera hablando" Como puede verse en la imagen, el quinteto vocal asume "sin sonido, solo teatral" un comportamiento en el que la referencia es oculta, velada. No es obvia al oído, pero constituye una parte determinante del devenir y el resultado sonoros. Este proceso, muy característico en la obra del compositor

${ }^{64}$ Donde confluían la mirada árabe y la occidental a través de un uso deliberado de la vocalidad del muecín árabe y del canto gregoriano.

${ }^{65}$ Comentario publicado en la partitura de la pieza, editada por Breitkopf \& Härtel, cedida por el compositor: "Fragmente, Straten, Polylektüren und verschiedenen Perspektive dieser Mottete-Chanson sind in diesem Sinn als Zeit-Kristallen und Raum-Fragmente (Ruinen) in Terrain vagues noch geblieben". Traducción del original alemán realizada por Nuria Núñez-Hierro.

${ }^{66}$ B-C. Han: La expulsión..., p. 114. 
andaluz, nos enfrenta a una superficie encriptada en la que la materia sonora puede palparse, puede asirse de alguna forma, con la connivencia estética del oyente.

\section{¡A resignificar $c^{* * * * * * *} !^{67}$ o Todos somos impropios ${ }^{68}$. A modo de conclusión}

En 2017, el cartel de la XIV edición del Festival de Cine Europeo de Sevilla, obra de la artista María Cañas (Sevilla, 1972), mostraba la imagen de una mujer que emergía de un gran ojo. Dicha imagen formaba parte de una de las muchas ilustraciones que realizó el pintor Walter Popp (Nueva York, 1920-Nueva Jersey, 2002) durante los años 50. Su reutilización, por parte de la artista sevillana, provocó un polémico revuelo mediático. Teniendo en cuenta la "acusación popular" ${ }^{69}$ que sufrió Cañas, decidimos que sería pertinente solicitarle una definición personal del término apropiación. Con ella abrimos las conclusiones a nuestro trabajo:

Sin la apropiación, la resignificación y la remezcla de nuestra memoria e imaginarios no hay cultura ni transmisión cultural. Estas prácticas enriquecen nuestra producción cultural. Todo trabajo creativo es derivado, nada es original y cuando una ley es injusta lo correcto es desobedecer. Creamos en un archivo vivo, no fuera del mundo sino en él, en constante crecimiento. En la onda de Derrida [...] el archivo en tanto que "ANARCHIVO", un archivo sin mandatos, que no sea necesariamente positivo y que no pudiera ser utilizado por las "distintas policías" como sistema de control. [...] El apropiacionismo propicia la liberación de las imágenes, la idea de cultura como construcción colectiva y el arte de las multitudes conectadas en la sociedad del siglo $\mathrm{XXI}^{70}$.

Esta definición se convierte en un manifiesto ético, estético y político acerca de cómo podría entenderse la creación artística: "archivo vivo", "construcción colectiva" y "de las multitudes conectadas". Pero también deja en evidencia a nuestro propio estudio, ya que muestra algunos de los aspectos que no hemos podido analizar. Por ejemplo, no hemos tratado las prácticas adheridas a principios como el trabajo colaborativo, el open access,

\footnotetext{
${ }^{67}$ Proclama empleada por María Cañas en su exposición No ni ná. Contenga multitudes, Santa Cruz de Tenerife, Tenerife Espacio de las Artes, 2019.

${ }^{68}$ Parafraseamos el título de la sección de conclusiones de Timothy D. Taylor: Music and Capitalism. A History of the Present, Chicago-Londres, The University of Chicago Press, 2016, p. 177: "Capitalism is People, Too", en una adaptación del ADN neoliberal que caracteriza a la sociedad contemporánea.

${ }^{69}$ Fácilmente constatable en textos como el de Alejandro Ávila: "¿Plagio o arte? El nuevo cartel del Festival de Cine de Sevilla siembra la polémica", eldiario.es, 9-9-2017. https://www.eldiario.es/andalucia/ lacajanegra/cine/Plagio-Festival-Cine-Sevilla-polemica_0_684881823.html (consulta 1-7-2019).

${ }^{70}$ María Cañas: "Amor apropiacionista", texto inédito escrito en torno a la pregunta ¿Qué es la apropiación?, solicitado por el autor y recibido, vía e-mail, el 6-2-2019.
} 
el procomún o las Open Content Licenses, que conciben la cultura como "un asunto de flujos, cambio y colaboración emergente [que] reclamaría que toda obra es derivada" 71 .

Tampoco hemos considerado debidamente el marco económico que subyace a toda práctica cultural contemporánea y que contempla la apropiación desde una perspectiva más industrial, jurídica y crematística. En este sentido, "saber cómo actúan las industrias culturales mainstream para observar las prácticas e ideologías capitalistas en acción [...] sería tan importante como estudiar el comportamiento de aquellos actores que se sitúan en la frontera de dichas industrias" 72 . Somos conscientes, en definitiva, del cúmulo de posibilidades analíticas que ofrece el fenómeno de la apropiación.

Podemos afirmar, en cambio, que los casos de estudio aquí expuestos nos orientan hacia intenciones muy dispares y, en algunos casos, opuestas. Las propuestas musicales adscritas a la creación académica contemporánea poco tienen que ver, en lo que se refiere al contexto desde el que se generan y las licencias estéticas y creativas que se permiten: el uso del muecín árabe en la obra de Sánchez-Verdú o del cantaor flamenco en la de Sotelo no generan reacciones significativas. De hecho, la categoría de lo impuro no es percibida de igual manera, si atendemos, por ejemplo, a las distintas acogidas que obtuvieron el estreno de El Público en el Teatro Real de Madrid ${ }^{73}$ o el de la Antología del Cante Heterodoxo en la XX Bienal de Flamenco de Sevilla ${ }^{74}$. Sería imprescindible considerar el contexto en el que ambas obras consiguieron su première para entender la expectativa generada y la mayor o menor frustración por parte del público.

Por otro lado, consideramos que el empleo crítico y subalterno de figuras de la memoria mayoritaria como Miguel Hernández o Federico García Lorca en la obra de Niño de Elche y Mauricio Sotelo, Rocío Márquez y Lagartija Nick, respectivamente, activa un imaginario intertextual y sonoro crítico, desde el que es posible indagar en narrativas contrahegemónicas de

\footnotetext{
${ }^{71}$ Definición extraída de Lawrence Liang por M. Villaespesa: "preludio. instrucciones de uso", en F. G. Gil, M. Villaespesa (eds.): Código Fuente..., pp. 40-53, p. 40.

72 T. D. Taylor: Music and Capitalism..., p. 182: "While it is imperative to know what the mainstream music cultural industries are doing in order to view capitalist ideologies and practices in action [...], it is just as important to attend to workers on the fringes of the mainstream cultural industries".

${ }^{73}$ Alberto González Lapuente: "Crítica de la ópera de Lorca: el espejo del público", Diario ABC, 25-22015 (https://www.abc.es/cultura/musica/20150225/abci-lorca-teatro-real-publico-201502250945.html, consulta 23-2-2019); o Antonio Hernández Nieto: "Lo contemporáneo se hace público", Sul Ponticello. Revista online de música y arte sonoro, 9-3-2015 (http://www.sulponticello.com/lo-contemporaneo-se-hace-publico/\#.XHFlwuhKjD4, consulta 23-3-2019).

${ }^{74}$ En este caso, sería necesario realizar un estudio específico y particular de la bipolaridad maniquea que afecta a la crítica musical flamenca. Por citar solo algunos ejemplos, Manuel Martín Martín: "El 'cancitidio' de Niño de Elche", Diario El Mundo, 26-9-2018 (https://www.elmundo.es/andalucia/2018/09/26/5bab3c78468aebe3298b466e.html, consulta 23-2-2019); o, desde la posición contraria, Carlos H. de Frutos: "El cero a la izquierda de Niño de Elche", ctxt.es. revista contexto, 29-9-2018 (https://ctxt.es/es/20180926/Culturas/21970/ Carlos-H-de-Frutos-flamenco-la-Bienal-del-Flamenco-concierto-critica.htm, consulta 23-2-2019).
} 
considerable interés. Así ocurre, también, con las propuestas de Flamante y ELEE feat. Een Pianist?, que, en una suerte de recreación flamenca digital, manipulan y degeneran estilos de la práctica ortodoxa para ofrecer una lectura tan contracultural como inquietante.

Siendo conscientes de lo aparentemente incoherente que resulta elogiar un término como apropiación, cuando buscamos vaciarlo de sentido y contenido, consideramos que ha quedado demostrada la insolvencia de su acepción negativa. Como afirma Rubén López Cano, sería necesario:

minar esa concepción (como la de préstamo o borrowing) que está cargada de ideología y conceptos implícitos, para sustituirlas por categorías operativas que vayan más allá de la noción de propiedad (apropiación implica que hay alguien propietario de aquello que se apropia) y que esta noción impide apreciar el fenómeno desde otro lugar que no sea la oposición: creación vs. plagio ${ }^{75}$.

La antropofagia -estética, artística y disciplinar- con la que abríamos nuestro texto no es más que una manera de denominar la actitud omnívora de la acción hermenéutica constante que rige nuestras vidas. Como dice Ouaknin: "Lo propio del hombre es no tener propiedad, su definición es no tener definición, el hombre debe inventarse, construirse, venir a ser""76.

Recibido: 27-2-2019

Aceptado: 30-5-2019

${ }^{75}$ Comunicación vía e-mail el 24-1-2019.

${ }^{76}$ M. A. Ouaknin: Elogio..., p. 25. 